\title{
Gedung Pertunjukan Musik Modern Dengan Pendekatan ARSITEKTUR EKSPRESIONISME Di SURAKARTA
}

\author{
Dhita Fardaniwuri, Suparno, Hari Yuliarso \\ Program Studi Arsitektur \\ Universitas Sebelas Maret Surakarta \\ Email : dhitafardaniwuri@gmail.com
}

\begin{abstract}
Surakarta is a city of art and culture. In accordance with the development of more advanced age, the development of music in Surakarta is also increasing, especially in modern music. Surakarta society has a high appreciation of the music that can be seen from the many festival band events and also modern music performances were held. The existence of places to perform the music in Surakarta has not meet the standards and requirements of the theater and also not representative enough in terms of architecture, so the purpose of this scheme is to obtain a building design that gives a forum for people to express their musical taste or become a means of entertainment to enjoy music itself. Modern Music Concert Hall in Surakarta is expected to facilitate the activities of modern music performances which are supported by relevant supporting facilities located in Surakarta. The issue is how the design of musical expression can be translated into the design of Modern Music Concert Hall using architectural design. The design of the building will show the expression and characteristics of modern music. Submission of image expression form, shown by the arrangement embodied in the design appearance of the building, the design of interior, exterior and support facilities of the building so that the building can reflect the activities in it..
\end{abstract}

Keywords: Auditorium, expressionism, modern music, music concert hall

\section{PENDAHULUAN}

Seni musik merupakan salah satu cabang kesenian, merupakan hasil karya seni kreatif di mana penciptanya tidak terlepas dari jasmani dan rohani manusia itu sendiri, kelompok maupun bangsa. Seni musik merupakan cabang seni yang mengutamakan media suara atau bunyi sebagai ungkapan perasaan dari penciptanya atau pemain. Musik adalah salah satu kebutuhan penting yang mengalami perkembangan dan penyempurnaan yang dimaksud untuk selalu memberi kepuasan bagi konsumen.

Sesuai dengan perkembangan zaman yang semakin maju, perkembangan musik di Surakarta juga semakin meningkat, di mana tuntutan masyarakat akan suatu wadah yang menampung kegiatan musik dengan fasilitas yang memadai harus dipenuhi. Belakangan ini banyak sekali bermunculan festival budaya yang mengangkat musik modern serta festival band yang digelar, khususnya di kawasan Surakarta.
Di Surakarta sendiri banyak musisi yang bermain musik secara amatir. Namun, musisi yang sukses menembus pasar musik nasional sangat sedikit atau boleh dibilang tidak ada. Untuk itulah diperlukan sebuah wadah atau tempat untuk meningkatkan daya saing dan kemampuan musisi musisi musik modern Surakarta agar dapat sukses di pasar nasional bahkan dunia. Perlunya musik modern untuk dikembangkan adalah karena semakin besarnya gelombang musik luar negeri masuk ke Indonesia.

Sarana dan prasarana musik di Surakarta sangat terbatas. Bahkan untuk gedung pertunjukan yang dirancang khusus untuk musik belum tersedia di Surakarta. Dari segi kualitas yang mencakup tata visual, audio dan akustik ruang kurang memenuhi persyaratan. Keamanan dan kenyamanan penonton kurang mendapat perhatian. Selain itu gedung pertunjukan yang ada hanya menyediakan wadah untuk menggelar pertunjukan yang dapat dinikmati oleh indera pendengar saja tanpa memperhatikan dalam segi ekspresi 
bermusik baik oleh pelaku musik/musisi maupun pengunjung penikmat musik.

Ruang pertunjukan musik merupakan sebuah tempat untuk mempertunjukan karyakarya seni yang dituangkan dalam sebuah pertunjukan musik. Untuk mempertunjukan musik, tentunya kita memerlukan sebuah tempat. Baik indoor maupun outdoor, sehingga pertunjukan tersebut dapat menghasilkan sound (suara) yang baik. Ruangan yang didesain untuk pertunjukan seringkali dihadapkan pada masalah kualitas suara dan akustik. Kesemuanya dapat diminimalkan apabila sudah dipertimbangkan dengan seksama pada saat ruangan tersebut didesain. Semua pengaturan atau design ruangan yang memiliki standar akustik dan visual akan sulit didapatkan atau dicapai apabila pertunjukan dilakukan di luar ruangan.

Pertunjukan musik diadakan untuk memberi hiburan kepada masyarakat. Pertunjukan musik juga selalu menghadirkan kesan ekspresif dari penampil sehingga dapat pula menumbuhkan ekspresi yang berbedabeda dari penonton dan dapat menumbuhkan minat masyarakat untuk menonton suatu pertunjukan yang merupakan ekspresi batin dari pemainnya.

Ekspresi berupa rasa dan gejolak akan mendesak untuk ditransformasikan keluar dari dalam diri seseorang melalui berbagai media perwujudan. Hal ini terjadi pada tahap proses kreatif penciptaan sehingga ekspresi tersebut merupakan jiwa yang membuat suatu ciptaan dimulai dalam proses perwujudannya. Proses perwujudan karya dalam bidang arsitektur dan interior akan menunjukkan bahwa ruang sebagai media ekspresi semakin terbukti melalui perwujudan bentuk, warna, dan tekstur (Yusita: 2003).

Sebuah gedung pertunjukan musik merupakan sarana untuk membangkitkan atau mengekspresikan kepekaan batin dan perasaan dari penampil maupun penonton. Gedung Pertunjukan Musik dapat mempengaruhi ekspresi kreatifitas bermusik. Penciptaan atmosfer ruang diperlukan penataan seperti cahaya, akustik, layout. Elemen-elemen tersebut sangat berpengaruh terhadap hasil penciptaan atmosfer ruang.

Gedung Pertunjukan Musik Modern ini ingin memacu kreativitas para pecinta musik melalui wujud bangunan yang ekspresif.
Wujud bangunan yang ekspresif inilah para musisi yang mengolah kemampuan mereka dipacu untuk dapat menumbuhkan jiwa kreatif dan bebas berekspresi pada karya-karya mereka. Alunan musik yang jujur dari ekspresi jiwa musisinya tersebut dapat terwujud dalam Gedung Pertunjukan Musik Modern dengan adanya karakter dinamis antara ruang dalam dan tampilan ruang luar.

\section{METODE}

Metode perancangan gedung pertunjukan musik modern dengan mentransformasikan konsep yang direncanakan menjadi desain yang dirancang. Desain dirancang dengan pendekatan Arsitektur Ekspresionisme yang diaplikasikan pada pengolahan tapak, bentuk dan ruang.

Metode yang digunakan bertujuan mendapatkan desain bangunan yang dapat mewadahi kegiatan pertunjukan musik modern, serta fasilitas pendukung terkait. Arsitektur Ekspresionisme ditransformasikan dalam desain melalui ekspresi dan karakteristik musik modern.

Perancangan pada bangunan akan menampilkan penyampaian citra ekspresi bentuk yang ditunjukkan melalui penataan perancangan tampilan bangunan, bentuk, serta perancangan ruang melalui penciptaan atmosfer ruang yang ekspresif melalui warna, tekstur dan ornamen-ornamen ruang yang digunakan, sehingga bangunan dapat mencerminkan kegiatan di dalamnya.

\section{ANALISIS}

\subsection{Analisis Peruangan}

Secara garis besar, berdasar bentuk kegiatan dan macam kegiatan yang direncanakan, kegiatan yang terjadi pada Pusat Pagelaran Musik adalah: kegiatan pertunjukan musik, kegiatan pendidikan musik, kegiatan romosi dan penjualan industri musik, kegiatan pengelola.

Tabel 1. Kebutuhan Ruang

\begin{tabular}{|c|l|l|}
\hline PELAKU & KEGIATAN & PERUANGAN \\
\hline $\begin{array}{l}\text { Pengunjung/ } \\
\text { Penonton }\end{array}$ & Datang & Hall penerima \\
\cline { 2 - 3 } & Menonton & $\begin{array}{l}\text { Auditorium } \\
\text { musik }\end{array}$ \\
\cline { 2 - 3 } & Kursus & R. kursus \\
\hline
\end{tabular}


Dhita Fardaniwuri, Suparno, Hari Yuliarso, Gedung Pertunjukan Musik Modern dengan Pendekatan ...

\begin{tabular}{|l|l|l|}
\hline & musik & musik \\
\hline \multirow{2}{*}{$\begin{array}{l}\text { Pelaku seni } \\
\text { musisi) }\end{array}$} & Datang & Hall penerima \\
\cline { 2 - 3 } & Persiapan & Backstage \\
\cline { 2 - 3 } & Pertunjukan & Auditorium \\
\hline
\end{tabular}

Pada Tabel 1. terlihat kebutuhan peruangan yang dibutuhkan dalam pemenuhan wadah gedung pertunjukan musik modern.

\subsection{Analisis Lokasi}

Selain menentukan lokasi yang strategis, memilih tapak dengan kondisi yang mendukung keberadaan gedung pertunjukan musik modern ini sangat menentukan prospek bangunan tersebut.

1. Tujuan

Mendapatkan lokasi yang sesuai dengan gedung pertunjukan.

2. Dasar pertimbangan:

Posisi tapak strategis untuk ekspose tampilan fisik bangunan, luasan tapak dapat menampung seluruh kebutuhan ruang yang direncanakan.

Lokasi tapak berada di Jalan Adi Sucipto, Kecamatan Laweyan sebagai lokasi yang tepat untuk Gedung Pertunjukan Musik Modern di Kota Surakarta. Tapak memiliki luas 30.000 m2. Eksisting tapak dapat dilihat pada Gambar 1.

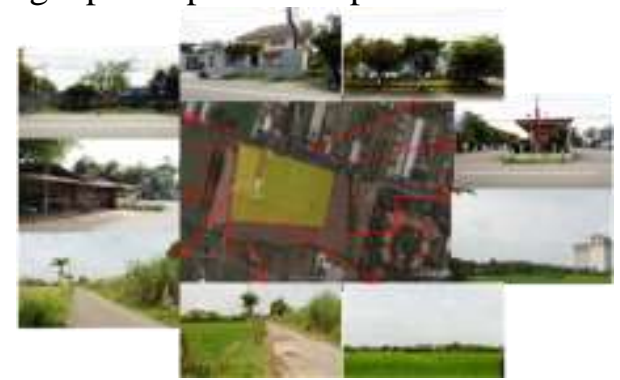

Gambar 1. Eksisting Tapak

Batas tapak

Utara : Jalan Adi Sucipto

Timur : Persawahan

Selatan : Persawahan

Barat : Jalan Lingkungan

\subsection{Analisis Pencapaian}

Pencapaian ke dalam bangunan harus mudah diakses, mudah dilihat dan memiliki sirkulasi yang aman akan menstimulus orang untuk masuk dalam area bangunan.

1. Tujuan: menentukan main entrane, menentukan service entrance

2. Dasar Pertimbangan: kemudahan akses, sirkulasi tapak yang aksesibel, arus kendaraan dan potensi jalan, tingkat keamanan.

3. Proses analisis

Main Entrance (ME)

Mudah dijangkau dan terlihat dengan jelas. Menghadap langsung ke arah jalan untuk kemudahan sirkulasi kendaraan masuk dan ke luar tapak.

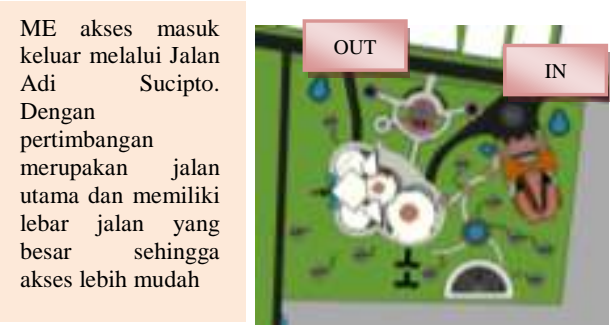

Gambar 2. Pola Pencapaian

Pada Gambar 2. merupakan akses pencapaian ke dalam bangunan.

\subsection{Analisis Pemintakatan (Penzoningan)}

Pemintakatan berdasarkan sifat kegiatan dan keadaan dalam tapak dilakukan sebagai acuan dalam penataan peruangan, namun tetap memperhatikan modul-modul struktur yang telah diterapkan.

1. Tujuan: Menentukan mintakat (zoning) berdasarkan sifat kegiatan dan keadaan pada tapak.

2. Dasar pertimbangan: analisis peruangan, analisis pengolahan tapak, analisis struktur.

3. Proses analisis: persyaratan ruang, berdasarkan kelompok kegiatan dan analisis pengolahan tapak.

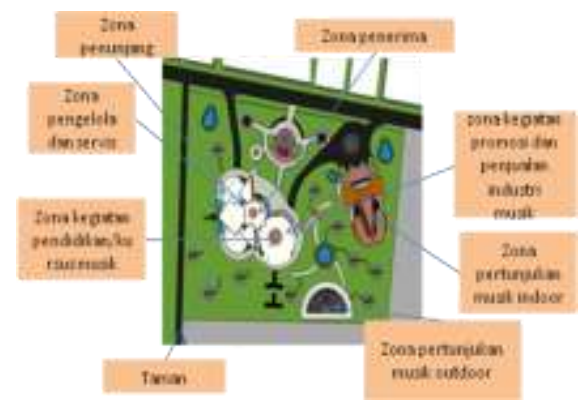

Gambar 3. Hasil Pemintakatan

\subsection{Analisis Bentuk dan Massa Bangunan}

\subsubsection{Analisis Bentuk Bangunan}

Bangunan Gedung Pertunjukan Musik Modern di Surakarta ditampilkan secara komunikatif, karakter yang ditampilkan 
mengekspresikan fungsi bangunan. Oleh karena itu bangunan dengan fasilitas kegiatan musik modern ditampilkan secara atraktif dan ekspresif. Bentuk massa dilihat dari atas merupakan modifikasi dari bentuk alat musik drum dan alat musik petik seperti terlihat pada Gambar 4.
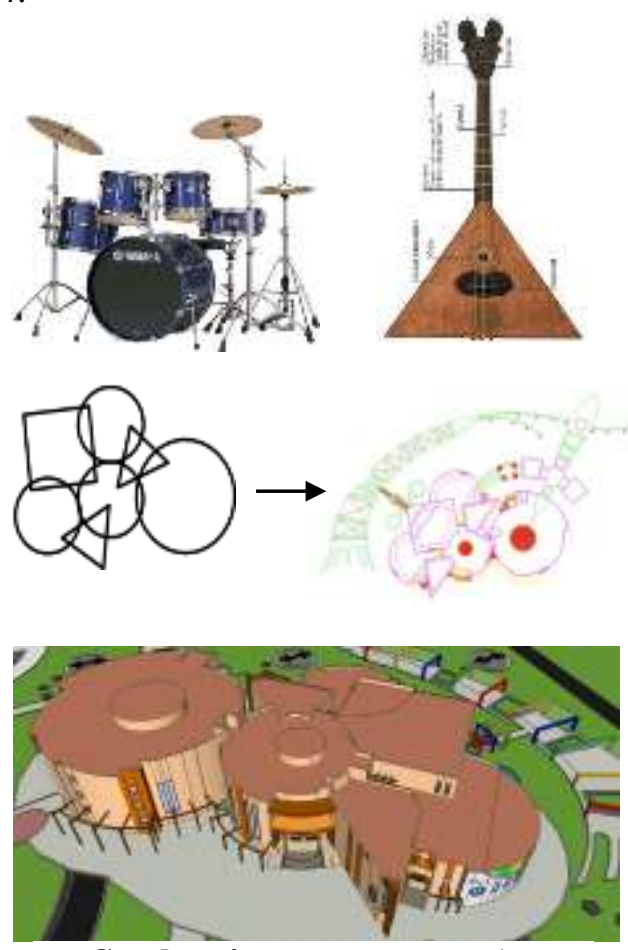

Gambar 4. Penataan Massa dan Bentuk Bangunan

\subsubsection{Analisis Bentuk Ruang Pertunjukan}

Pemilihan bentuk lantai merupakan salah satu hal penting untuk menentukan kinerja akustik suatu ruang. Bentuk lantai auditorium pagelaran musik yang digunakan mempengaruhi rangkaian sumber-jejaktransmisi-penerima.

Berdasarkan pertimbangan tersebut direncanakan bentuk panggung kipas seperti terlihat pada Gambar 5, karena memiliki keuntungan secara akustik yaitu penonton lebih dekat dengan panggung serta bentuk lengkung dapat mewadahi lebih banyak penonton dalam luas area yang sama.

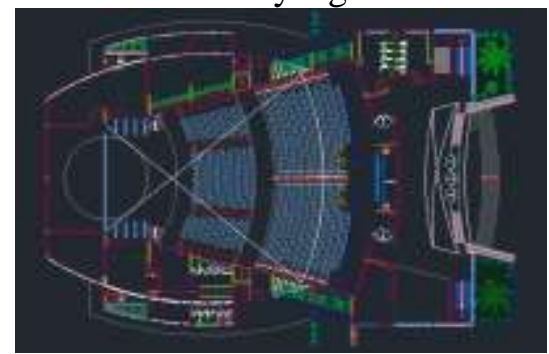

Gambar 5. Bentuk Ruang Pertunjukan

\subsection{Analisis Penampilan dan Karakteristik Bangunan}

Bangunan Gedung Pertunjukan Musik Modern di Surakarta ditampilkan secara komunikatif, karakter yang ditampilkan harus dapat mengekspresikan fungsi bangunan dan mudah dikenal oleh masyarakat. Oleh karena itu bangunan dengan fasilitas kegiatan musik modern ditampilkan secara atraktif dan ekspresif. Untuk menunjukkan karakter atraktif dan ekspresif dengan menampilkan bentuk yang bangunan yang dinamis. Kedinamisan dapat diwujudkan dengan tatanan massa yang mengalir.

Melalui alat musik grand piano, ekspresi emosi perasaan musisinya, seperti perasaan senang, sedih, kecewa, takut, dalam musik dapat dibaca oleh penikmatnya. Bentuk dan filosofi piano tersebut memberi inspirasi untuk menerapkannya karakter dinamis pada bangunan Gedung Pertunjukan Musik Modern yang terlihat pada Gambar 6.

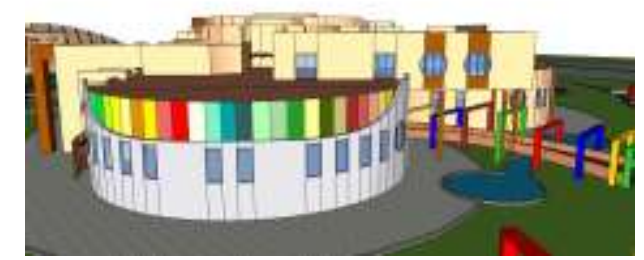

Gambar 6. Tampilan dan Karakteristik Bangunan

Gambar 7. menunjukkan penggunaan warnawarna putih, cerah seperti merah, oranye, biru, mampu membangkitkan kreatifitas pengguna bangunan Gedung Pertunjukan Musik Modern. Penerapan warna antar bidang diberi suatu gradasi dengan maksud memberi karakter dinamis pada bidang bangunan.

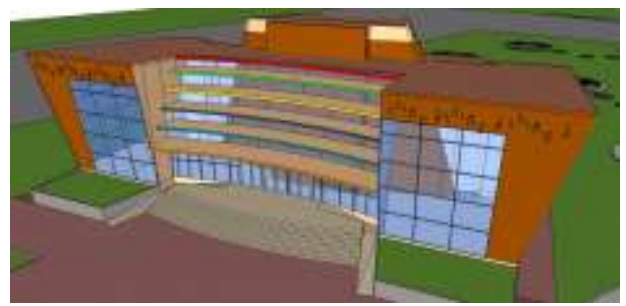

Gambar 7. Tampilan Fasad Bangunan 


\subsection{Analisis Akustik Bangunan}

Dalam sebuah gedung pertunjukan musik, hal yang paling ditekankan adalah tentang aksutik ruangan. Banyak area-area vital yang membutuhkan penekanan akustik seperti concert hall dan studio musik.

Akustik dibutuhkan untuk menghasilkan suara yang maksimal di ruangan tersebut sekaligus menghindari terjadinya kebocoran suara yang dapat merembes ke luar ruangan.

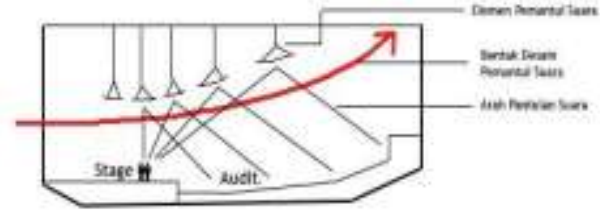

Gambar 8. Pengolahan Akustik Pada Area Auditorium

Persyaratan utama yang harus dipenuhi dalam perancangan tata akustik gedung pertunjukan menurut Doelle (1990:54) adalah: kekerasan (loudness) yang cukup dengan cara memperpendek jarak penonton dengan sumber bunyi. Bentuk ruang yang tepat, distribusi energi bunyi yang merata dalam ruang, ruang harus bebas dari cacatcacat akustik dan pengolahan elemen pembentuk ruangnya (lantai, dinding dan plafond) dengan bahan penyerap bunyi dan bahan yang berfungsi akustik seperti acoutical board maupun bahan-bahan lunak yang berpori lainnya. Keberadaan plafond yang memenuhi syarat baik bahan maupun bentuk penampangnya juga mutlak, untuk menghindari melemahnya suara.

Penggunaan lantai yang keras dan tidak dapat ditembus (batubata, beton) dan tidak dilapis hanya akan menyerap kurang dari 5\% suara dan memantulkan hampir $95 \%$.

Pemasangan karpet diseluruh permukaan lantai, pemasangan tirai dan penggunaan kursi penonton dengan jok yang empuk juga sangat membantu penyerapan bunyi yang sangat dibutuhkan untuk menghasilkan bunyi yang nyaman didengar.

\subsection{Analisis Struktur Bangunan}

Struktur atap bangunan (upper structure) menggunakan rangka baja ringan dan beton dak. Struktur badan (super structure) yang digunakan adalah struktur rangka dinding dengan kolom dan balok dan rigid frame.
Pondasi yang dipilih sebagai sub structure untuk bangunan adalah pondasi sumuran dan footplat.

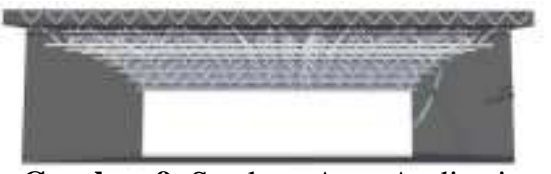

Gambar 9. Struktur Atap Auditorium

Gambar 9. menunjukkan penggunaan struktur atap pada auditorium menggunakan atap baja ringan.

\section{KESIMPULAN (KONSEP DESAIN)}

Konsep rancangan gedung pertunjukan musik mengacu pada pendekatan Arsitektur Ekspresionisme, konsep ekspresionis pada desain ditunjukkan pada:

\subsection{Rencana Tapak}

Rancangan tapak merupakan wujud dari penggabungan antara berbagai analisis tapak seperti analisis ruang, tapak, bangunan, persyaratan ruang, sistem struktur, sistem utilitas seperti terlihat pada Lampiran.

\subsection{Desain Bangunan}

Desain ini merupakan hasil dari analisis.

\subsubsection{Penampilan dan Perancangan}

Bangunan Gedung Pertunjukan Musik Modern di Surakarta ditampilkan secara komunikatif, penggunaan warna-warna cerah serta ornamen-ornamen musik pada fasad semakin memperkuat fungsi bangunan. Fasad bangunan juga menggunakan kaca-kaca untuk memaksimalkan pencahayaan alami, seperti terlihat pada Gambar 10.

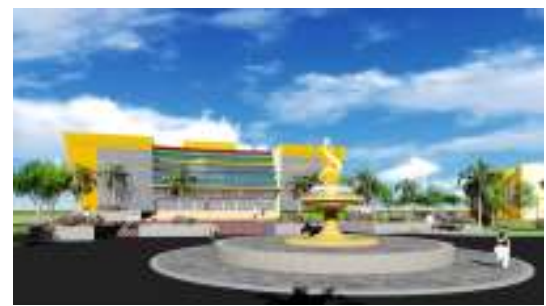

Gambar 10. Perspektif Tampilan Bangunan Massa A

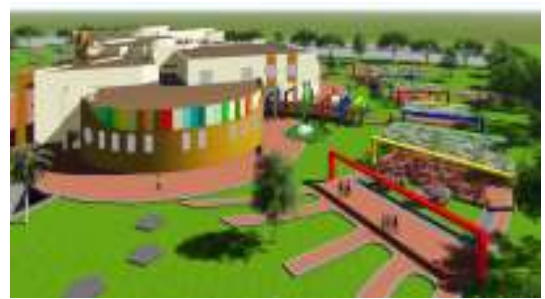

Gambar 11. Perspektif Bangunan Massa B 
Pada Gambar 11. menunjukkan pola garis yang diterapkan pada bentuk-bentuk bangunan. Kesan bergerak diberikan sesuai dengan fungsinya. Musik menunjukkan pergerakkan dan irama yang mengalir serta penggunaan ornamen garis yang membentuk tuts piano.

\subsubsection{Ruang Dalam / Interior}

Pada penataan ruang dalam auditorium diterapkan permainan warna sesuai karakter ruang dengan kombinasi warna cerah dan soft serta meminimalkan ornamen agar penonton bersemangat dan lebih fokus dalam menikmati pertunjukan musik, seperti pada Gambar 12.

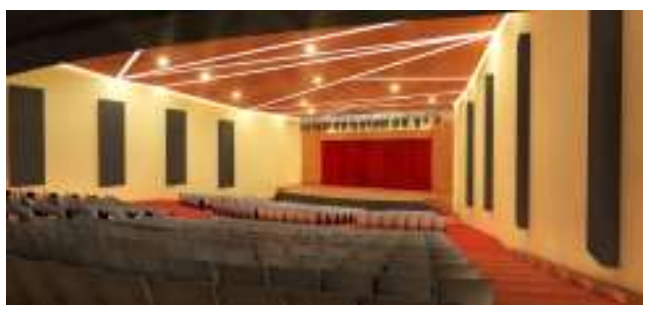

Gambar 12. Perspektif Auditorium

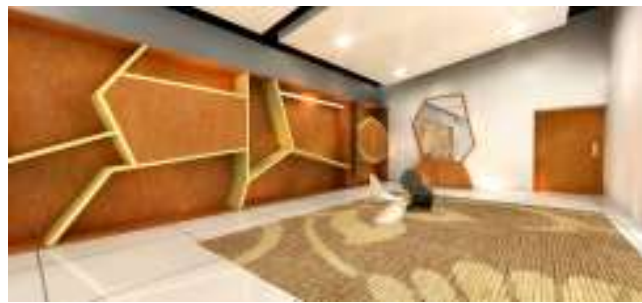

Gambar 13. Perspektif Backstage

Pada Gambar 13. penggunaan ornamen yang lebih dinamis pada backstage serta permainan plafond yang miring.

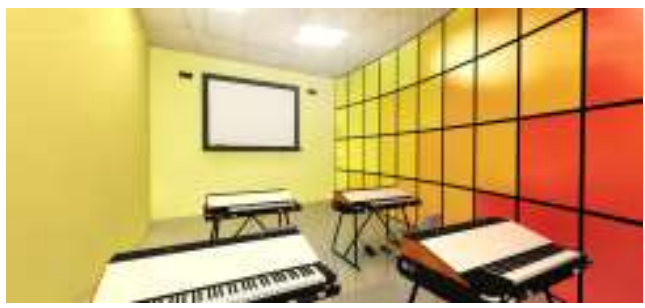

Gambar 14. Perspektif Ruang Kelas Kursus Musik

Pada Gambar 14. menunjukkan pada ruang kelas pelatihan, dibutuhkan suasana yang bersemangat, memacu kreativitas.

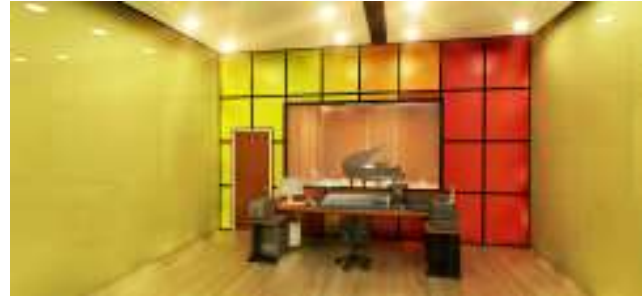

Gambar 15. Perspektif Studio Rekaman

Pada Gambar 15. penggunaan garis garis tegas sebagai ornamen bertujuan agar dalam studio rekaman lebih fokus dan bersemangat.

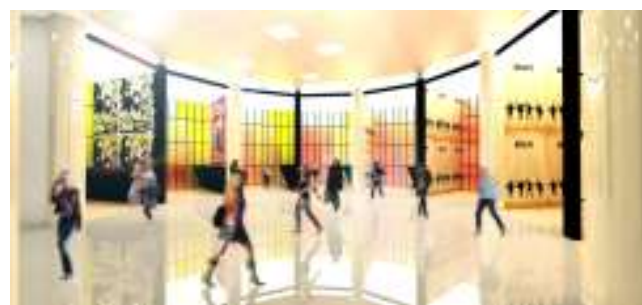

Gambar 16. Perspektif Ruang Promosi Musik

Pada Gambar 15. dan Gambar 16. penggunaan warna pada ruang lebih soft dengan tujuan pengunjung lebih santai dan nyaman.

\subsubsection{Ruang Luar / Eksterior}

Memaksimalkan ruang luar atau lansekap sebagai ruang publik yang memiliki fungsi sebagai ruang ekspresi.

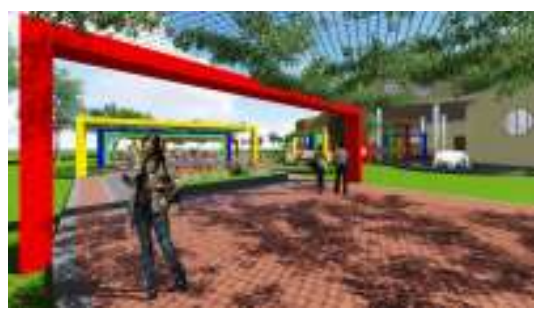

Gambar 17. Perspektif Taman

Pada Gambar 17. menerapkan elemen-elemen warna pada taman dengan penggunaan tiangtiang dengan warna-warna cerah pada selasar ruang luar .

Elemen taman softscape yang digunakan seperti tanaman dengan warna mencolok untuk membangkitkan semangat dan kreatifitas serta lebih eksresif seperti pada Gambar 18. 


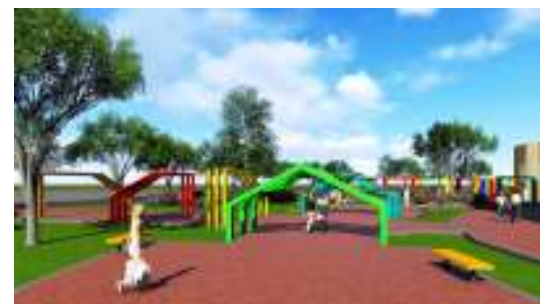

Gambar 18. Perspektif Selasar Taman

\section{REFERENSI}

Doelle, Leslie L., Eng., M. Arch., 1990, Akustik Lingkungan, Surabaya : Penerbit Erlangga.

Kusumarini, Yusita, 2003, Ruang Sebagai Media Ekspresi Dan Apresiasi, Jurnal Dimensi Interior: 29-45.

Pengaruh Warna dalam Ruang Terhadap Kondisi Fisik dan Psikologis Manusia, http://www.kompasiana.com/fransiska.t/pe ngaruh-warna-dalam-ruang-terhadapkondisi-fisik-dan-psikologismanusia_5500caf9a333119a72511f4e, Diakses 26 Maret 2016. 
Lampiran. Rencana Tapak

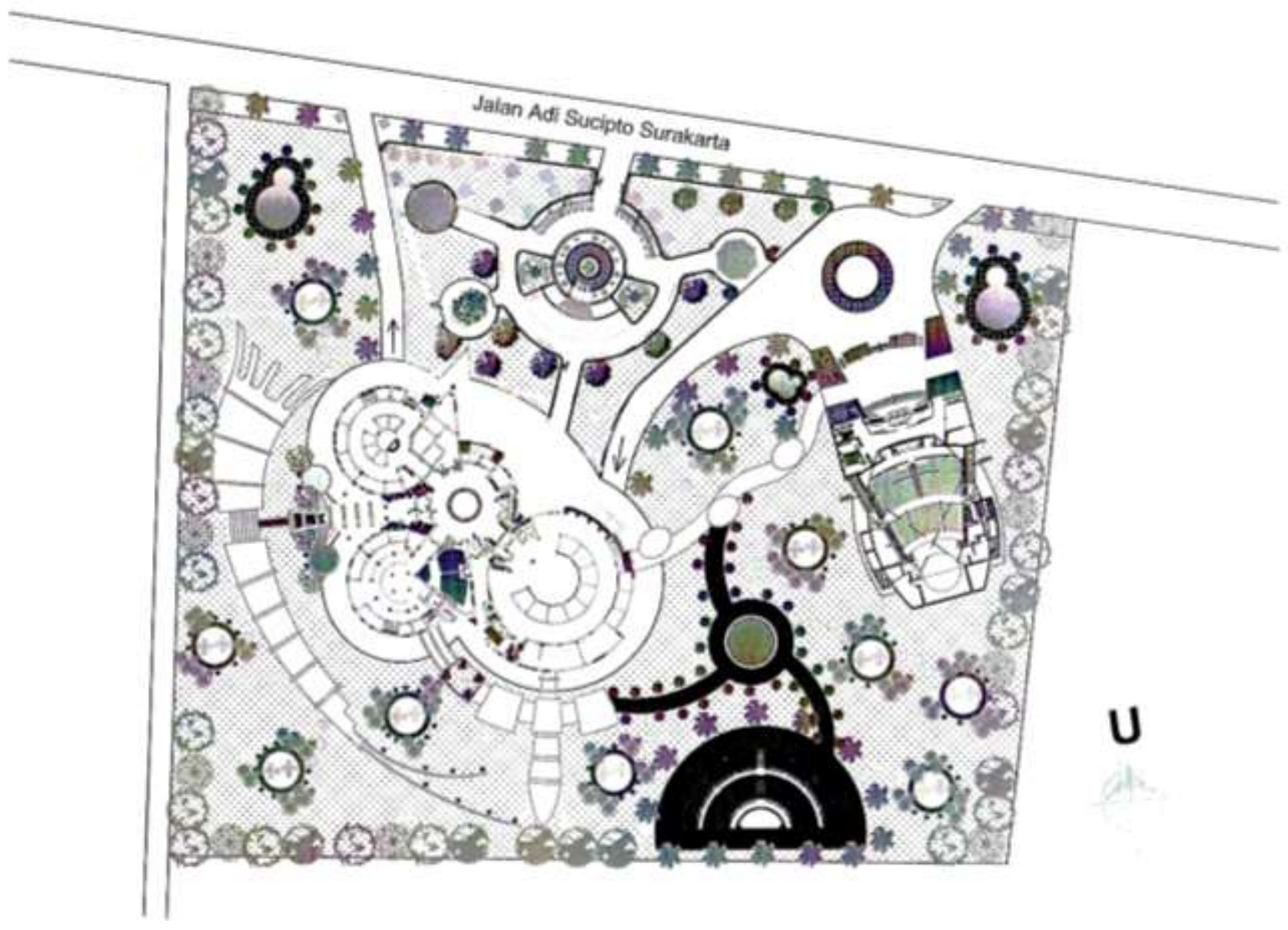

